\title{
A dimensão imaginária e intersubjetiva das organizações de saúde: implicações para o trabalho gerencial e para a mudança organizacional
}

\author{
Imaginary dimension and intersubjectivity \\ in public health organizations: implications to managerial work \\ and organizational change
}

Creuza da Silva Azevedo ${ }^{1}$

${ }^{1}$ Escola $N$ acional de Saúde Pública, Fundação Oswaldo Cruz. Rua Leopoldo Bulhões 1480/Sala 716, M anguinhos. 21041-210 Rio deJaneiro RJ. creuza@ensp.fiocruz.br
Abstract This paper deals with organization management in a new perspective, stressing the micro-social aspects and the role of individuals in the process of implementing change in public health organizations such as hospitals. Following the paths of French psychosociology, the article approaches the imaginary, intersubjective and collectivedimensions of these organizations, highlighting the ways hospitals' directors and employees engage themselves in a struggle for power, affiliation and recognition. An essentially interactive and intersubjective activity, management is examined in the light of psychoanalysis's leadership function. It seems crucial to take into account the directors' potential structuring role in order to understand the organizational changing processes. N evertheless, the mounting crisis in Rio de Janeiro public health services does not favor change and the building of personal bonds, but disruption, dismantle of institutional affiliations. In this scenario, the management structuring function and the director's social and psychological mediating role lose ground.

Key words Intersubjectivity and management, Organizational imaginary, Psychosociology and management in public health
Resumo Este artigo objetiva explorar caminhos teóricos para analisar a articulação entre a dinâmica intersubjetiva e a construção de processos de mudança em organizações públicas de saúde, discutindo particularmente o papel do gestor neste contexto. Para considerar o fenômeno organizacional, a perspectiva da psicossociologia francesa éapresentada, ganhando destaquea compreensão da dimensão imaginária, grupal e inconsciente dasorganizações. 0 trabalho gerencial, compreendido particularmente através da função de liderança, étratado à luz de uma perspectiva grupal, de base psicanalítica, sendo ressaltado seu potencial estruturante para as organizações. Embora os gestores de organizações de saúde possam potencialmente propiciar 0 embate entre as forças dominantes do conformismo eas forças instituintes, que favorecem o vínculo e a mudança, a crise de natureza gerencial e assistencial que vivem os hospitais públicos leva a um esvaziamento das capacidades de intermediação social e psíquica desses gestores.

Palavras-chave Intersubjetividade e gestão, Trabalho gerencial e imaginário, Psicossociologia e gestão em saúde 
Introdução

As organizações se apresentam como representações, por excelência, da objetividade - produzem bens e serviços, enfim, universo ondereina a racionalidade. Pouca atenção tem sido dada à compreensão dos processos organizacionais enquanto expressão de ambiguidades e incertezas, advindas de seu caráter humano e social. As teorias organizacionais tratam os recursos humanos como "fator de produção", "objeto da gestão" ou, mais recentemente, "cúmplices e entusiastas da empresa" ${ }^{1}$.

Em torno das dificuldades de implementação de processos de mudança envolvendo novos modelos gerenciais e novas formas de organização do trabalho nas organizações públicas de saúde, particularmente nos hospitais públicos, progressivamente temos procurado novas "Ientes"2, enfocando a relação entre subjetividade e gestão, os aspectos microssociais e o papel dos sujeitos, particularmente através da teoria psicanalítica e da perspectiva da psicossociologia francesa, queinclui entreas suas preocupações a análise das organizações.

A emergência do tema do sujeito no campo da saúde coletiva, particularmente no âmbito do planejamento e gestão, vem se expressando também nos trabalhos de Campos ${ }^{3,4}$, Cecílio ${ }^{5,6}, \mathrm{Ce}$ cílio e $M$ endes ${ }^{7}$, Cecílio e M erhy ${ }^{8}$, M ehry ${ }^{9}$, Onocko Campos $^{10,11}$ e Ayres ${ }^{12}$, seja pelo reconhecimento dos limites da racionalidade político-estratégica para tratar dos processos de mudança nas organizações de saúde, como da dimensão intersubjetiva do cuidado em saúde. No que se refere mais especificamente a nossa linha de investigação, temos procurado compreender a dimensão intersubjetiva einconsciente dos processos organizacionai $s^{13-15}$, procurando uma aproximação entreos referenciais da psicossociologia e da psicanálise e o campo da gestão em saúde.

Este artigo objetiva então explorar caminhos teóricos para analisar a articulação entre a dinâmica intersubjetiva e a construção de processos de mudança em organizações públicas de saúde, discutindo particularmenteo papel do gestor neste contexto. Para considerar o fenômeno organizacional, a perspectiva da psicossociologia francesa é apresentada, ganhando destaque a compreensão da dimensão imaginária, grupal e inconsciente das organizações. 0 trabalho gerencial é tratado à luz de uma perspectiva grupal, de base psicanalítica, sendo ressaltado seu potencial estruturante para as organizações, compreendido particularmente através da função de liderança.
Buscando articular a discussão teórica com 0 contexto atual dos hospitais públicos, são recuperados al guns resultados de investigação recentemente realizada ${ }^{13,14}$.

A abordagem da psicossociologia francesa seinteressa pelo indivíduo em situação, recusando-se a separar o indivíduo e o coletivo, o afetivo e o institucional, os processos inconscientes e sociais. Como uma vertente da psicologia social, enfoca grupos, organizações e comunidades em situações cotidianas. Seus estudos propiciam explicações sobre a constituição e evolução dos vínculos entre os indivíduos, sobre a dinâmica social e seus processos de mudança.

A organização éconsiderada, nesta visão, uma realidade viva, onde os sujeitos vivem seus desejos de afiliação, onde se instaura não somente 0 jogo do poder, mas também o do desejo, apresentando-se como cenário para paixões presididas pelo amor etambém pela violência ${ }^{16,17}$. É central nesta perspectiva ateoria psicanalítica deFreud, incorporando também elementos da filosofia e sociologia contemporâneas, com destaque para o pensamento de Cornelius Castoriadis.

0 fenômeno organizacional passa a ser por nós tratado a partir da dimensão imaginária, intersubjetiva e grupal, particularmente através da leitura de Eugène Enriquez ${ }^{17}$. Assim, a possibilidade de acordos e projetos coletivos com base, exclusivamente, em argumentos racionais équestionada. A interação nas organizações envolve os sujeitos e, assim, a dimensão do desejo, da pulsão, do afeto, do imaginário e do simbólico.

Para compreender a organização, é necessário então admiti-la como fruto do cruzamento de projetos racionais e conscientes, advindos da cena voluntária, e também de fantasias e desejos que são operantes, que afetam a vida psíquica dos indivíduos e grupos, conformando uma outra cena: a do inconsciente e do imaginário.

\section{O fenômeno organizacional na visão da psicossociologia}

Enriquez ${ }^{16,17}$ considera a organização como um sistema cultural, simbólico eimaginário, ondese destacam a compreensão do papel do sujeito, dos processos grupais, de seu sistema de valores e a construção de seu imaginário social ${ }^{17}$. Toda organização dispõe de um sistema de normas evalores procurando levar seus membros a certo modo de apreensão do mundo, buscando orientar suas ações. Tal processo de socialização e as representações sociais assim conformadas encon- 
tram equivalência, do ponto de vista psíquico, em imagens compartilhadas pelos sujeitos sobre as organizações a qual pertencem, conformando um imaginário social mais ou menos interiorizado pelos seus membros. Assim, a organização e o trabal ho adquirem sentido para os indivíduos não somente por seus imaginários individuais, mas também por uma dinâmica psicossocial ea conformação de um imaginário social.

O imaginário social ao nível das organizações étido por Enriquez ${ }^{17}$ como espaço de articulação das necessidades psíquicas dos indivíduos às necessidades funcionais das organizações. Os sujeitos se ligam à organização por vínculos não ape nas materiais mas, acima de tudo, afetivos e imaginários². As organizações são objeto de transferência, não só espontânea, mas também induzida, mostrando-se capazes de satisfazer as necessidades narcísicas dos indivíduos ${ }^{15}$. Como espaço para o jogo do reconhecimento, as organizações procuram capturar os indivíduos em seus próprios desejos de afirmação narcísica edeidentificação ${ }^{17}$. Os processos deidentificação, basepara os processos de adesão/laço social, permitem ao sujeito o sentimento de inclusão no mundo.

Embora o imaginário seja sempre desreal, tenha uma base fantasmática, para Enriquez ${ }^{16,17}$, é também o que fecunda o real, buscando fazer do real expressão de seu próprio sonho. Ele funda uma dinâmica criativa: sem imaginário não há projeto, não há utopia, nem mundo a construir ${ }^{16}$.

Para examinar em profundidade a questão imaginária, Enriquez ${ }^{17}$ nos remete não somente à teoria psicanalítica mas também ao pensamento filosófico de Cornelius Castoriadis em sua análise da dinâmica imaginária na sociedade ea dialé tica criação/alienação.

\section{A função imaginária eas organizações}

Castoriadis ${ }^{18}$ afirma que é impossível e inconcebível a história fora da imaginação criadora, que chamou de imaginário radical, manifestação de um universo de significações. Assim, atarefa fundamental de toda sociedade seria a produção de sentido, possibilitando apreender e conceber as relações dos seres e das coisas.

Para Castoriadis, existe nas coletividades humanas uma potência de criação, chamada de imaginário social instituinte - fluxo incessante de representações, desejos, afetos. Através da socialização, de certo modo, esta imaginação é sufocada, produzindo-se então a heteronomia, como expressão da conformidade e repetição.
H eterônomos tornam-se a sociedade e grande parte dos indivíduos que fazem julgamentos em função de "convenções e da opinião pública"19.

Embora as instituições tendam a se cristalizar, dando origem ao que 0 autor chamou de imaginário social instituído, "[...] ]assegurando a reprodução das mesmas formas [...]"19, 0 imaginário instituinte poderá sempre se expressar, portador então de novas significações sociais.

0 imaginário social/organizacional seria para Enriquez " [...] uma certa maneira de representar para nós aquilo que somos, o que queremos ser, o quequeremos fazer em que tipo de sociedadee de organização desejamos intervir ou existir" ${ }^{20}$. É um sistema de interpretação, de produção de sentido que surge na interação e encontra-se articulado ao desejo dos sujeitos.

A tão esperada adesão dos indivíduos aos projetos organizacionais pode ser resultado de dois processos que, na realidade, são combinados e que decorrem da produção de um sistema imaginário organizacional ${ }^{17}$. No primeiro caso, a organização, através do imaginário produzido, seapresenta como instância capaz de responder aos desejos narcísicos de reconhecimento e potência do indivíduo, assegurando proteção. A coesão obtida seria defensiva, uma tentativa de prender os indivíduos nas suas ilusões/fantasmas de onipotência. A organização seria uma grande referência, fonte de identidade, mostrando-se como benevolente e nutriz, mas também como castrado$\mathrm{ra}^{17,21}$. Estaríamos frente ao excesso de sentido quetem como efeito matar a invenção ea criatividade ${ }^{22}$. Tal contexto engendraria então conformismo e negação da autonomia dos sujeitos.

Podemos compreender que à heteronomia e ao imaginário enganoso se contrapõe outra possibilidade apontada por Enriquez ${ }^{17,20:} 0$ imaginário motor. Imaginários enganoso e motor expressariam a dialética criação/alienação, a tensão entre $o$ indivíduo, suas possibilidades de se mostrar sujeito afirmando sua diferença, e a organização, que procura obter coesão buscando homogeneidade. Embora o imaginário enganoso seja alvo de críticas do autor, Enriquez ${ }^{16}$ também vem alertar que a idéia de desalienação total é mistificadora, pois a vida em organizações impõe, em algum nível, certa identificação alienante para que haja identificação mútua.

0 imaginário motor seria possível quando os grupos admitem a diferenciação de seus membros e, assim, uma visão não monolítica do projeto comum, favorecendo a criatividade, introduzindo a diferença, em oposição à repetição, possibilitando então considerar a cooperação como 
fruto do tratamento deconflitos, permitindo pensá-los como a raiz de mudanças e práticas sociais inovadoras. N estaperspectiva, o laço social seforja permitindo aossujeitos existirem de maneira mais autônoma no conjunto social ${ }^{17,20}$. Neste contexto, haveria a possibilidade de criar uma fantasmática comum que compreen de uma experiência com os outros, avaliada e refletida, preservando o sonho e a possibilidade de mudança, comportando ainda a experimentação e o pensamento questionador. A construção do imaginário motor apresenta-se sempre como um desafio.

Como dito antes, o imaginário éo que fecunda o real e, enquanto abertura, preserva a possibilidade da mudança. Entre os dois tipos de imaginário, há a tendência a desenvolver o imaginário enganoso. 0 imaginário motor, ressalta Enriquez ${ }^{17}$ a partir de Winnicott, implica um certo "espaço transicional" que possibilite a transgressão, o prazer de viver em conjunto, o humor, o prazer estético, a criatividade feliz, todos fundamentais à atividade reflexiva. 0 imaginário motor, instituinte, mostra-se portanto como um desafio às regras organizacionais. Porém, paradoxalmente, as organizações precisam também de "barulho" e desordem para saírem da entropia ${ }^{23}$. Portanto, entre 0 imaginário enganoso e motor está o dilema organizacional de favorecer uma identidade coletiva aos seus membros, na qual se apóia, e o exercício da singularidade dos sujeitos.

Enfim, considerar a dimensão imaginária é compreender a complexa dinâmica entre os indivíduos e as organizações, entre os sujeitos e o coletivo, implicando uma outra perspectiva para analisar a cena organizacional, particularmente quando pensamos situações de crise e processos de mudança.

\section{Intersubj etividade e projetos coletivos}

Serão tratados a seguir os processos grupais, imprescindíveis para discussão das possibilidades de constituição de projetos coletivos e de processos de mudança nas organizações públicas de saúde e para entendermos teoricamente o papel dos seus dirigentes.

Consideramos a gestão como um trabalho necessariamente interativo, que se realiza entre sujeitos, um trabalhar sobre outros trabalhos ${ }^{24}$ emergindo necessariamente no contexto intersubjetivo ${ }^{14}$ devendo, portanto, ser analisado sob 0 prisma grupal.

O grupo, para a psicanálise, é objeto deinvestimento psíquico e pulsional, resulta de projeções de seus membros ${ }^{25}$, constituindo-se, portanto, não apenas como lugar de acordos objetivos, mas também como espaço imaginário e de manifestação do inconsciente. Para Enriquez ${ }^{17}$, o grupo é visto como portador de um projeto ou frente a uma tarefa a cumprir. 0 processo identificatório grupal teria por base o projeto comum. Porém, participar de um projeto, de futuro em comum, implica sonhá-lo, supõe abrir espaço para a ilusão ${ }^{26}$, possibilitando recriar vínculos e, assim, se contrapor a representações do outro como perseguidor ${ }^{11}$, por vezes dominantenas organizações. Essas são questões fundamentais para a compreensão da construção deum projeto coletivo como uma experiência humana e intersubjetiva.

Enriquez ${ }^{17,20}$ chama a atenção também para conflito estrutural presente nos grupos e seus participantes, entre o reconhecimento do desejo e o desejo de reconhecimento. De um lado, se coloca o desejo de cada um de se fazer percebido e aceito na sua diferença, em sua palavra e originalidade. De outro lado, a necessidade de ser reconhecido como membro do grupo, identificado com seus pares, representando a busca da identidade e, no seu extremo, a massificação. A organização é, portanto, atravessada pela luta por reconhecimento. Sentimentos de exclusão ou de não reconhecimento podem engendrar desejos de retaliação, podendo ser fonte de hostilidade e de mobilização de pequenos grupos para ações violentas atravessadas até mesmo pelo desejo de aniquilamento do outro - profissional, dirigente, liderança.

0 conflito entre reconhecimento do desejo e desejo de reconhecimento pode engendrar dois caminhos. Quando édominantea busca da identidade, há uma redução da capacidade reflexiva e de inventividade, não sendo tolerados conflitos. No caso de terem primazia processos de diferenciação, apresenta-se no grupo uma visão não monolítica do projeto comum e, ao mesmo tempo, as possibilidades de suscitar adesão surgem através de um processo de negociação. A perspectiva de cooperação se associa, então, ao tratamento de conflitos. N este processo, destaca-se a importância do líder, que evitaria a desagregação do grupo, que buscaria, por sua vez, ser gerido de forma democrática. É a perspectiva democrática que se norteia pelo direito de todos à palavra. Neste contexto, surge a possibilidade de representar vontades e desejos do grupo, permitindo, em algum nível, coesão e identificação ${ }^{17}$. Esse caminho recoloca a perspectiva de Enriquez acerca da construção do "imaginário motor" e 0 desafio organizacional de propiciar, ao mesmo 
tempo, a construção de uma identidade coletiva e o exercício da singularidade dos sujeitos. Para essa construção, apostamos na função de liderança e na construção de processos mais democráticos nas organizações.

A aproximação da abordagem da intersubjetividade ao campo da gestão e das organizações possibilita, como estamos tentando mostrar, compreender outros elementos explicativos eprodutores de efeitos na vida organizacional, particularmente para tratar as questões do trabalho em equipe, da cooperação, do trabalho gerencial, da conformação de projetos de mudança. É fundamental, como aponta Onocko Campos ${ }^{11}$, que os dirigentes compreendam as mediações intersubjetivas que se desenrolam no palco grupal.

A partir da leitura psicossociológica, os processos de mudança apóiam-se no favorecimento à circulação da palavra e autonomia dos sujeitos e na possibilidade de construção de outros imaginários na organização que possam abrir brechas no imaginário dominante.

A função deliderança: a perspectiva deK aës e a categoria de intermediário

A perspectiva psicanalítica de RenéKaës éfundamental para a compreensão teórica do funcionamento dosgrupos, do papel da liderança, apresentando-secomo uma importante base para a compreensão da prática gerencial e compreendermos o que está em jogo em processos de mudança.

Apoiando-se em textos de Freud, Kaës ${ }^{27-29}$ propõe a construção de uma metapsicologia intersubjetiva. Esse autor trabalha com a categoria de intermediário e aponta as possibilidades de sua utilização para o enfrentamento do problema da articulação psicossocial. Para Kä̈s ${ }^{30}$, "ministros, chefes, dirigente, líder realizam funções psíquicas intermediárias eencarnam essa função".

Kaës ${ }^{27-29}$ compreende as formações e processos psíquicos intermediários como formações de ligação, de passagem de um elemento a outro, exercendo no espaço interpsíquico o papel de mediadores, representantes, objetos transicionais, porta-vozes.

Uma característica importante dessas formações intermediárias é, portanto, o seu "caráter biface", de relação entre o elemento eo conjunto, propiciando a ligação/rearticulação entre elementos distintos, separados, funcionando em campos heterogêneos, atravessados por conflitos ${ }^{30}$.

As formações intermediárias asseguram então as condições psíquicas da vida da instituição:
[...] contribuem para a sua permanência e para a sua capacidade de engendrar a continuidade; para a sua estrutura e para a sua capacidade estruturante; [... ] e consequentemente para a definição da sua identidade ${ }^{30}$.

Enfim, as formações e processos psíquicos intermediários entreos sujeitos singulareseo grupo asseguram a continuidade e propiciam a articulação entre a psique dos sujeitos e a realidade do grupo. Assim, a pessoa, objeto ou pensamento intermediário funciona como operador deidentificações imaginárias e simbólicas, podendo favorecer a construção de processos de mudança.

A gestão e os próprios dirigentes, na difícil posição de governar, cumprem então, em tese, essa função de passagem e articulação entre as questões de governo, de condução da organização e interesses e desejos dos vários grupos de trabalhadores, de fortalecimento do laço social, podendo propiciar uma outra experiência da grupalidade ${ }^{10}$ efavorecer a construção de novos sentidos para o trabalho e de novos imaginários na organização. Estamos aqui considerando o papel potencial do gestor, mas certamente essa função pode ser exercida por outras lideranças ou pelo próprio projeto.

A mudança, o papel dos dirigentes e o contexto atual dos hospitais públicos

O tema da mudança tem sido por nós destacado a partir de reflexões que articulam a realidade vivida nas organizações de saúde e a perspectiva psicossociológica². Os resultados de pesquisa apresentados por Azevedo, Fernandes et al. ${ }^{13} \mathrm{e}$ Azevedo $0^{14}$ são aqui recuperados para apoiar as reflexões teóricas desenvolvidas.

Mas afinal, quando falamos de processos de mudança, de que está se tratando? Consideramos certa compreensão que vem atravessando 0 movimento sanitário ${ }^{31,32}$. Não se trata de qualquer mudança, mas sim da construção de processos que fortaleçam a dimensão pública e social das organizações de saúde, expressando a defesa da saúde como direito do cidadão, dever do Estado e a democratização da gestão do sistema de saúde. Tais mudanças devem levar a uma nova forma de organização dos serviços e a renovação dos processos de gestão, propiciando maior responsabilidade institucional para com os resultados do trabalho, buscando enfrentar o "desinteresse, a alienação, 0 agir mecânico" ${ }^{3}$.

No entanto, o contexto atual dos serviços públicos desaúde, particularmentedos hospitais, 
atravessado por crises de natureza política, ge rencial e assistencial, marcado pela baixa governabilidadeebaixo investimento ${ }^{13-15}$, configuraum cenário particularmentefavorecedor de vivências de desamparo e desafiliação social26,33, conformando um clima de desconfiança e dificuldades de cooperação. Tal contexto dificulta o investimento libidinal dos profissionais no trabalho e na organização, mostrando-se, portanto, adverso às mudanças pretendidas, particularmente à construção de projetos mais coletivos.

Em nossa compreensão ${ }^{13,14}$, as organizações públicas de saúde estão vivendo sob o domínio de um imaginário enganoso constituído em um contexto de reconhecimento negativo ${ }^{33-35}$ - de desvalorização do serviço público e de seus funcionários, de precarização das condições de trabal ho, da remuneração e dos vínculos, fruto também do contato cotidiano com a miséria da população, com seu sofrimento social ${ }^{33}$ e com o quedeirrepresentável se apresenta ${ }^{11,13,14}$. Tal imaginário estaria perpassado pelo domínio da impotência, da descrença, da impossibilidade da mudança, determinando apatia e conformismo e tendo repercussões éticas na relação entre os trabalhadores e com os pacientes. Este imaginário dominante vem, em nossa compreensão, na verdade, corroendo o imaginário do movimento sanitário, dos gestores/profissionais/intelectuais.

N este cenário, compreendemos a prática ge rencial como espaço potencial para embates entre as forças dominantes do conformismo, da heteronomia, forças disjuntivas, e as forças instituintes, que procuram favorecer o vínculo, a ligação, o reconhecimento do trabalho dos profissionais nas suas diferenças, enfim podendo propiciar algum nível de identificação com as organizações públicas de saúde e sua missão.

Compreendemos, em acordo com outros autores do campo da gestão, como O nocko Campos $^{10}$ e Campos Ca $^{4}$ que os modelos de gestão que procuram uma base participativa e a valorização de dispositivos coletivos, tais como colegiados de gestão, reuniões entre setores, processos de planejamento estratégico, embora possam representar riscos de manipulação, podem, por outro lado, permitir pactos, acordos quanto aos rumos da organização, contribuindo para uma capacidade estruturante, possibilitando o surgimento de outras falas ${ }^{13}$. Discutir "o que fazer" é criar brechas para pensar o futuro e possibilitar sair da inércia ligada ao imaginário da impotência e da urgência e abrir espaço para a construção de outro imaginário, mais criativo e menos aprisionado à repetição.
As experiênciasqueprocuram desenvolver um plano de trabalho para os hospitais - a construção deum projeto assistencial egerencial - euma visão de futuro, podem ser propícias, em nossa visão, à constituição do que Castoriadis ${ }^{18,19} \mathrm{de}$ nominou de novas significações imaginárias, de um novo imaginário que possa ser compartilhado por alguns grupos na organização, ainda que permaneça em conflito com o imaginário dominante, que alimentaria a compulsão à repetição.

Adotando a perspectiva de Kaës ${ }^{36}$, os dispositivos coletivos podem mostrar-sepropíciosà construção subjetiva, particularmente ao exercício de funções psíquicas pelo grupo ou pelo líder, funcionando como um espaço para a realização da função intermediária, favorecen do a ligação entre os membros do grupo. Esses espaços coletivos suscitam processos transicionais, podendo talvez cumprir a função de restabelecimento de uma área de ilusão ou de sonho e a construção de novas simbolizações sobre o trabal ho nos hospitais.

A partir de Käes ${ }^{27}$ e da compreensão do trabalho do dirigente no seu sentido mais grupal, destaca-seentão o exercício de funções psíquicas inconscientes. 0 dirigente de um serviço de saúde, como personagem do grupo, pode mostrarse como aquele que porta e transporta o sujeito no grupo: funções de sustentação, apoio, representação e porta-ideal. Enfim, potencialmente uma função de articulação psicossocial.

Embora explorando caminhos teóricos que permitam analisar a articulação entreintersubjetividade e a construção de processos de mudança, não deixamos de lado, no entanto, o reconhecimento dos elementos que atuam no sentido contrário, de resistência à mudança, de desconstrução do vínculo social, fundamentais na compreensão da dinâmica atual das organizações de saúde. Tratamos anteriormente, apoiados em Castoriadis eEnriquez, da dinâmica existenteentreas forças disjuntivas, da heteronomia que constituem a base para o imaginário enganoso, dominante, e aquelas que procuram favorecer os vínculos, reconhecendo os conflitos e a diferença como base da construção coletiva, como espaço instituinte. Trataremos agora da manifestação da violência como expressão do vínculo social, ou do ataque aos vínculos nas organizações de saúde.

Os hospitais/serviços de saúde mostram-se também como espaço para manifestação de hostilidade e violência. A violência nas organizações se expressa como mal-estar, ataques, boicotes, comportamentos autoritários, proliferação de mentiras ecomportamentos paranóides por parte de indivíduos e grupos ${ }^{16}$. 
Em relatos de experiências em hospitais públicos do município do Rio de Janeiro ${ }^{13,14}$, seus diretores tratam de situações de crise, enfrentamentose, por vezes, exonerações traumáticas. Os obstáculos são muitos: há um conjunto de determinações de origem externa - pressões políticas, escassez de recursos, condições de abastecimento efuncionamento deficientes, precariedadena política de recursos humanos. Os diretores se deparam com as pressões de fornecedores, com a "privatização" dos hospitais pelos interesses políticos e corporativos de toda ordem. Do ponto de vista interno, manifestam-se as coalizões de poder, emergindo adesões, mas também oposições.

Em algumas experiências, o intuito da dire ção de reorganização do processo de trabalho e de engendrar uma melhor qualidade da assistência e maior responsabilidade institucional portanto maior compromisso e dedicação dos profissionais, particularmente dos médicos, mobiliza grande oposição e conflitos. N este contexto, o "denuncismo" se opõe a um caminho propositivo. É forte a atividade sindical buscando a exoneração de diretores. Como indicadores do desgoverno e descontrole, surgem a "rádio corredor", os abaixo-assinados, os inquér itos ${ }^{13,14}$.

Enquanto manifestação degrupo, a violência mostra-se como ataque ao vínculo que liga chefe e subordinados, trabalhadores e organização, como ataque às possibilidades de mudança e à constituição de uma nova liderança. As organizações, favorecendo a luta pelo poder, mostramse como campo propício à pulsão de morte em sua ação disjuntiva ${ }^{16,17}$.

Apoiados em Kaës ${ }^{29,30}$, podemos também supor quea violência manifesta edirigida aos diretores dos hospitais e às suas práticas gerenciais pode ser uma resposta dos profissionais àquilo que elas representam em termos de ameaça aos pactos e alianças inconscientes do grupo. Tais alianças ou pactos denegativossão formações psíquicasinconscientes que podem alimentar a ilusão grupal, enquanto estado de alienação, ou encobrimento de processos e afetos insuportáveis para os sujeitos. No caso dos serviços de saúde, por exemplo, tais pactos podem assumir a função psíquica de não representação pelostrabalhadores/profissionais de saúde daquilo que não se sentem capazes de responder; marcar uma separação ou um afastamento com relação à população e seu sofrimento; encobrir a baixa responsabilidade dominante nos serviços de saúde, mascarando a violência simbólica na relação dos profissionais com os pacientes ${ }^{15}$.

Tais alianças e pactos podem ficar sob o risco de ruptura a partir do modo como a função de liderança é exercida e dos compromissos éticopolíticos dos gestores. 0 ataque ao vínculo com o gestor pode então ser compreendido como retaliação, uma reação à ameaça de dissolução desses pactos.

Considerando com Enriquez que "todo comportamento implica ao menos duas significações [...]: a que a realidade histórica lhe dá e a que a realidade psíquica Ihe fornece" ${ }^{117}$ e que há uma imbricação constante entre o nível social e psíquico ${ }^{26}$, podemos compreender a hostilidade e violência nas organizações de saúde não apenas como expressão da dimensão política, mas também, em outro nível de análise - como manifestação de processos intersubjetivos, das lutas narcísicas, das resistências à mudança, de domínio da heteronomia e das forças instituídas.

A crise crônica/aguda vivida pelos hospitais públicos de emergência, particularmente no Rio de aneiro, com contornos dramáticos entre 2004 e 2005, caracteriza-se por uma situação deintensa precariedade. Os hospitais foram se tornando espaço para manifestação de diversas formas de violência, de degradação, de desvalorização da vida, configurando então um quadro de mudanças, no entanto, para pior: os hospitais públicos tornaram-se palco de cenas dramáticas, expressando a dificuldade de atender eser atendido $0^{13,14}$. Tal situação se traduz por uma desregulação total, expressando-se na experiência subjetiva, organizacional e social como desconstrução ${ }^{37}$.

Assim, a função de liderança, função estruturante e teoricamente favorecedora de processos de criação e de constituição de novas significações imaginárias, mostra-se muito fragilizada. Tal contexto se apresenta, portanto, particularmente propício a falhas ou quebra na função psíquica intermediária $a^{27,29,38}$, categoria tão enfaticamente destacada ao longo deste artigo.

Tendo por base a leitura psicanalítica sobre a importância teórica da função de liderança para a constituição do laço social, éimportante ser enfático quanto ao papel intersubjetivo que os gestores/diretores exercem nas organizações. Como dissemos ao longo de todo o trabalho, a função psíquica potencialmenteexercidapelo chefeéestruturante $e^{29,38}$, podendo ser propícia à coesão, à identificação eao tratamento de conflitos. Assim, ataques à função de liderança e ao que ela representa, enquanto possi bilidades deligação, de criação deuma área de ilusão, podem indicar um ataque aos vínculos entre os sujeitos na organização, fortalecendo a compulsão à repetição e a fragmentação.

É importante destacar que a situação de de gradação das condições de trabal ho nos hospitais 
públicosimpõeuma crisequevai além da gerencial e assistencial, emergindo como uma crise também desentido. Tal cenário minimiza as possibilidades de afiliação e os vínculos de pertencimento. Compreendemos então que a situação vivida nos serviços públicos de saúde parecepor em xequeas crenças que asseguram a base narcísica de pertencimento do sujeito ao conjunto social ${ }^{36}$.

\section{Considerações finais}

Finalizando, apoiados na perspectiva psicossociológica e psicanalítica, é essencial diminuir as ilusões quanto à possibilidade de organizações harmoniosas e reconciliadas. A imagem dos hospitais como arquipélagos e da gestão construindo pilares e pontes para articulação é expressiva, tanto da pluralidade de vínculos e projetos que os indivíduos estabelecem na organização, como do seu atravessamento por conflitos ealianças e, assim, da função estruturante da gestão.

Considerando com Castoriadis ${ }^{18}$ a dinâmica sempreexistente entreheteronomia eautonomia, provocar algum nível de descentramento é abrir caminhos para sair da clausura organizacional. Para o trabalho gerencial, implica o desenvolvimento de práticas que possam superar a forte e insidiosa metáfora da organização como máquina. Práticas que consigam ir além do olhar tecnocrático, instrumental e mesmo estratégico, podendo considerar as questões dos sujeitos, dos grupos, a problemática da identificação, do reconhecimento, das lutas narcísicas, da violência, abrindo possibilidades para novos ol hares e no- vas falas, reconhecendo a precariedade e contingências como parte da vida organizacional.

É preciso aumentar a compreensão dos dirigentes sobre o que está em cena nos processos organizacionais, na prática gerencial, nos dispositivos coletivos e de seu papel neles. A dimensão humana presente nas organizações não se limita à política, aos interesses; é preciso reconhecer as organizações como "campo passional e pulsional" 23. Torna-se então fundamental o emprego de dispositivos grupais que favoreçam, através de uma abordagem clínica, ecolocando os profissionais edirigentes em posição de palavra, a compreensão das relações dinâmicas entre organização, sofrimento e produção de sentido ${ }^{22}$. Tal desafio apresenta-se tanto para os processos de intervenção nas organizações de saúde, como naqueles voltados para formação gerencial. N este sentido, vale citar a experiência piloto do "Laboratório de Práticas Gerenciais" ${ }^{39}$, um dispositivo grupal por nós desenvolvido com diretores de hospitais, exalunos do curso de Especialização em Gestão Hospital ar da Escola deSaúdePública, entre 2000 e2002, que objetivou possibilitar aos gestores refletir e explorar as suas vivências sobre a dinâmica organizacional, particularmente relativas aos processos de mudança e as dimensões afetiva e imaginária presentes nas organizações.

Assim, finalizo este trabalho procurando realçar a complexidade dos processos de mudança nas organizações - compreendidos como construção social, política e imaginária, seu alto grau de incerteza e seu longo tempo de maturação, impondo uma visão mais modesta quanto às possibilidades de regulação e governabilidade. 


\section{Referências}

1. Aktouf O. A administração da excelência: da deificação do dirigente à reificação do empregado (ou os estragos do dilema do rei Lear nas organizações). In: Davel E, Vasconcelos J, organizadores. Recursos humanos e subjetividade. Petrópolis:Vozes; 1997. p. 242-266.

2. Azevedo CS, Braga Neto FC, Sá, MC. 0 indivíduo e mudança nas organizações de saúde: contribuições da psicossociologia. Cad Saude Publica 2002; 18(1):235-247.

3. Campos GWS. Considerações sobre a arte e a ciência da mudança: revolução das coisas e reforma das pessoas: 0 caso da Saúde. In: Cecílio LCO, organizador. Inventando a mudança na Saúde. São Paulo: Hucitec; 1994. p. 29-88.

4. Campos GWS. U m método para análise e co-gestão de coletivos: a constituição do sujeito, a produção do valor de uso e a democracia em instituições: 0 método da roda. São Paulo: Hucitec; 2000.

5. Cecílio LCO. Autonomia versus controle dos trabaIhadores: a gestão do poder no hospital. Cien Saude Colet 1999; 4(2):315-329.

6. Cecílio LCO. É possível trabalhar o conflito como matéria-prima da gestão em saúde? Cad Saude Publica 2005; 21(2):508-516.

7. Cecílio LCO, M endes TC. Propostas alternativas de gestão hospitalar e o protagonismo dos trabalhadores: por que as coisas nem sempre acontecem como os dirigentes desejam? Saúde soc. 2004; 13(2):39-55.

8. Cecílio LCO, Merhy EE. A integralidade do cuidado como eixo da gestão hospitalar. In: Pinheiro R, $M$ attos RA, organizadores. Construção da integralidade: cotidiano, saberes e práticas em saúde. Rio de Janeiro: IMS/UERJ, ABRASC0; 2003.

9. M erhy EE. Saúde: cartografia do trabalho vivo. São Paulo: Hucitec; 2002.

10. Oncko Campos R. A gestão: espaço de intervenção, análise e especificidades técnicas. In: Campos GWS, organizador. Saúde Paidéia. São Paulo: Hucitec; 2003.

11. Onocko Campos R. O encontro trabalhador-usuário na atenção à saúde: uma contribuição da narrativa psicanalítica ao tema do sujeito na saúde cole tiva. Cien Saude Colet 2005; 10(3):573-583.

12. Ayres JRCM. O cuidado, os modos de ser (do) humano e as práticas de saúde. Saúde soc. 2004; 13(3):16-29.

13. Azevedo CS, Fernandes MIA, Carreteiro, TC. Sob o domínio da urgência: a prática de diretores de hospitais públicos do Rio de janeiro. Cad Saude Publica 2007; 23(10):2410-2420.

14. Azevedo CS. Sob o domínio da urgência: o trabalho de diretores de hospitais públicos do Rio de Janeiro [tese]. São Paulo (SP): Instituto de Psicologia, Universidade de São Paulo; 2005.

15. Sá MC. Em busca de uma porta de saída: os destinos da solidariedade, da cooperação e do cuidado com a vida na porta de entrada de um hospital de emergência [tese]. São Paulo (SP): Instituto de Psicologia, Universidade de São Paulo; 2005.

16. Enriquez E. Les jeux du pouvoir et du désir dans l'éntreprise. Paris: Ed. Desclée Brouwer; 1997.
17. Enriquez E. A organização em análise. Petrópolis: Vozes; 1997.

18. Castoriadis C. A instituição imaginária da sociedade. Rio de Janeiro: Paz e Terra; 1982.

19. Castoriadis C. Figuras do pensável. As encruzilhadas do labirinto VI. Rio de Janeiro: Civilização Brasileira; 2004.

20. Enriquez E. O vínculo grupal. In: Levy A, Nicolai $A$, Enriquez E, Dubost J, organizadores. Psicossociologia: análise social e intervenção. Petrópolis: Vozes; 1994. p. 56-69.

21. Enriquez E. O trabalho da morte nas instituições. In: Kaës R, Bleger J, Enriquez E, Fornari F, Fustier $P$, Roussillon $R$, Vidal JP, organizadores. A instituição e as instituições: estudos psicanalíticos. São PauIo: Casa do Psicólogo; 1991. p. 73-102.

22. Levy A. Ciências clínicas e organizações sociais - sentido e crise de sentido. Belo Horizonte: Autêntica/ FUMEC; 2001.

23. Enriquez E. Vida psíquica e organização. In: M otta $F P$, Freitas ME, organizadores. Vida psíquica e organização. Rio de Janeiro: Editora Fundação Getúlio Vargas; 2000. p. 11-22.

24. Scharaiber LB, Peduzzi M, Sala A, Nemes MIB, Castanhera ERL, Kon R. Planejamento, gestão e avaliação em saúde: identificando problemas. Cien Saude Colet 1999; 4(2):221-242.

25. Anzieu D. 0 grupo e 0 inconsciente: 0 imaginário grupal. São Paulo: Editora Casa do Psicólogo; 1990.

26. Carreteiro TC. A doença como projeto: uma contribuição à análise de formas de afiliações e desafiliações sociais. In: Bader S, organizador. As artimanhas da exclusão: análise psicossocial e ética da desigualdade social. Petrópolis:Vozes; 2001. p. 87-95.

27. Kaës R. La parole et le lien. Paris: Dunod; 1994.

28. Kaës R. La invencíon psicoanalitica del grupo. Buenos Aires: Associacíon Argentina de Psicologia y Psicoterapia de grupo; 1994.

29. Kaës R. 0 grupo e o sujeito do grupo: elementos para uma teoria psicanalítica do grupo. São Paulo: Casa do Psicólogo; 1997.

30. Kaës R. Realidade psíquica e sofrimento nas instituições. In: Käes R, Bleger J, Enriquez E, Fornari $F$, Fustier $P$, Roussillon $R$, Vidal JP, organizadores. A instituição e as instituições: estudos psicanalíticos. São Paulo: Casa do Psicólogo; 1989.

31. Cecílio LCO, organizador. Inventando a mudança na saúde. São Paulo: Hucitec; 1994.

32. M endes EV. U ma agenda para saúde. São Paulo: Hucitec; 1996.

33. Carreteiro TC. Sofrimentos sociais em debate. Psicologia USP 2003; 14(3):57-72.

34. Carreteiro TC. Exclusion sociale et construction de I'identite. Paris: Éditions L'Harmattan; 1993.

35. Carreteiro TC. História de vida: da genealogia a um estudo. Psico (Porto Alegre) 2003; 34(2):281-295.

36. Kaës R. 0 intermediário na abordagem psicanalítica da cultura. Psicologia USP 2003; 14(3):15-34.

37. Giust-Deprairies F. Crise. In: Barus-Michel J, Enriquez E, Lévy A, organizadores. Vocabularie de Psychosociologie. Paris: Editions Éres; 2002. p. 108-117. 
38. Kaës R. Os espaços os psíquicos comuns e partilhados: transmissão e negatividade. São Paulo: Casa do Psicólogo; 2005.

39. Sá M C, Azevedo CS. Trabalho gerencial e processos intersubjetivos: uma experiência com diretores de hospitais públicos. Rev. Adm. Pública 2002; 36(1):507-527.

Artigo apresentado em 03/12/2007

Aprovado em 19/03/2008

Versão final apresentada em 10/04/2008 